\title{
Symmetry Analysis and Conservation Laws of a Family of Non-linear Viscoelastic Wave Equation
}

\author{
Maria Santos Bruzon ${ }^{1}$ and Almudena Marquez ${ }^{2}$ \\ ${ }^{1}$ University of cadiz \\ ${ }^{2}$ Universidad de Cádiz
}

August 3, 2020

\begin{abstract}
This work considers a non-linear viscoelastic wave equation with non-linear damping and source terms. We analyse the partial differential equation from the point of view of Lie symmetries. Firstly, we apply Lie's method to obtain new symmetries. Hence, we transform the partial differential equation into an ordinary differential equation, by using the symmetries. Moreover, new solutions are derived from the ordinary differential equations. Finally, by using the direct method of multipliers, we construct low-order conservation laws depending on the form of the damping and source terms
\end{abstract}

\section{Hosted file}

MMAS_BM_7.pdf available at https://authorea.com/users/348398/articles/473733-symmetryanalysis-and-conservation-laws-of-a-family-of-non-linear-viscoelastic-wave-equation

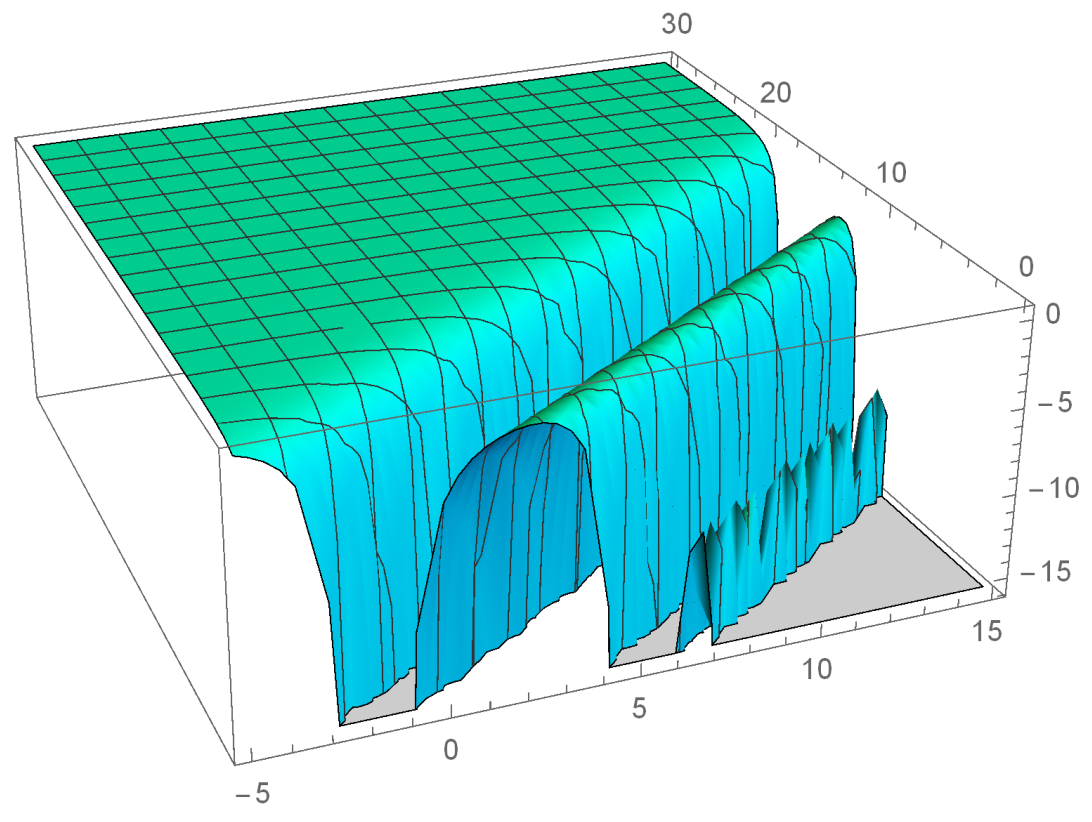




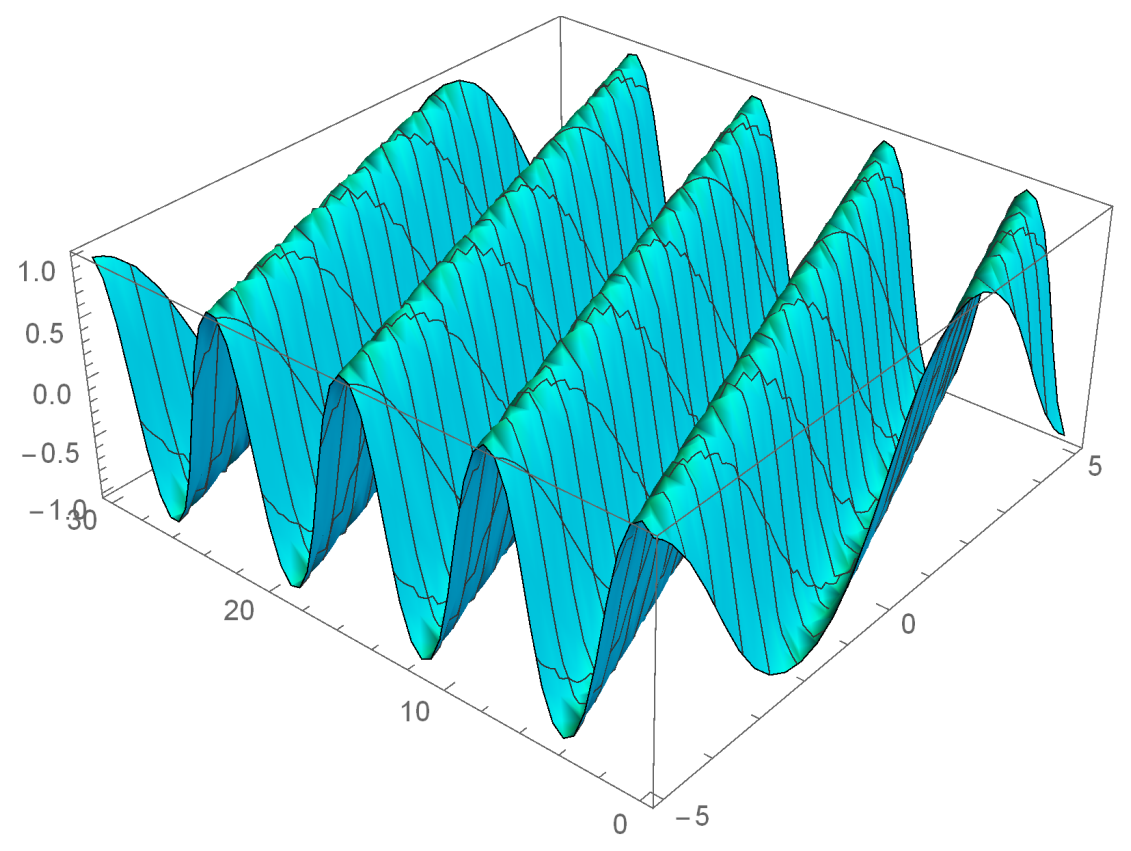

